\title{
SIMULATION AS A TOOL IN CONSTRUCTION MANAGEMENT
}

\section{Biljana Matejević-Nikolićn ${ }^{1 *}$ Lazar Živković}

The Faculty of Civil Engineering and

Architecture,

Nis, Serbia

\begin{abstract}
:
Advances in technology and modern systems have enabled a major shift in the presentation of reality in a virtual way. The representation of a real system using a model enables various experiments, analyzes and studies. In this paper, a general overview of modelling and simulation is given. Through a brief description of methods and techniques, a special review of the simulation in construction management is given. Processes and phenomena in construction are mostly of stochastic character, so it is very convenient to apply simulation for their computer representation. Also, the cyclicity of most processes in construction, as well as their dynamics provides a suitable basis for the application of simulation. Simulation is often used to solve various problems in construction management, as: optimization, predicting, allocation of resources, solving transportation problems, supply chains, selection of machinery, etc. Simulation methods are described and an overview of the software most commonly used in construction management is given.
\end{abstract}

Keywords:

Modelling, Simulation, Construction management, Simulation software.

\section{INTRODUCTION}

Advances in technology and modern systems provide a number of possibilities and create an environment that enables the visualization and creation of virtual reality. Modelling and simulation make up a series of creation activities model of a real system and its computer simulation. For more than four decades, modelling and simulation have been in use in various fields of science and technology. It is practically an essential and inseparable part of all scientific fields, for example, in the management of organizations and business systems, engineering, military industry, medicine, computer science, biology, education, but increasingly also in the social sciences. Modelling methods have been perfected with the development of applied mathematics, mathematical statistics, operational research, experimental and computer methods. The accelerating advances in technology, computing, and science have enabled a major shift in the representation of reality in a virtual way for an ever-increasing range of systems. 
The representation of a real system using a model enables various experiments, analyzes and studies. Simulation modelling is one of the leading modern methods of computer-aided modelling. It is in fact an abstract representation of a real system, valid only for strictly defined experimental conditions. This method enables the description, understanding and quantitative analysis of complex dynamic systems in different areas: production, transport, economics, mass service, computing, etc. In this paper, a general overview of modelling and simulation and a special review of the simulation in construction management are given.

\section{MODELLING AND SIMULATION IN CONSTRUCTION MANAGEMENT}

Processes and phenomena in construction are mostly of stochastic character, so it is very convenient to apply simulation modelling for their computer representation. Also, the cyclicity of most processes in construction, as well as their dynamics provides a suitable basis for the application of simulation. The methodology in modelling, as shown on Figure 1, is based on a closed cycle.

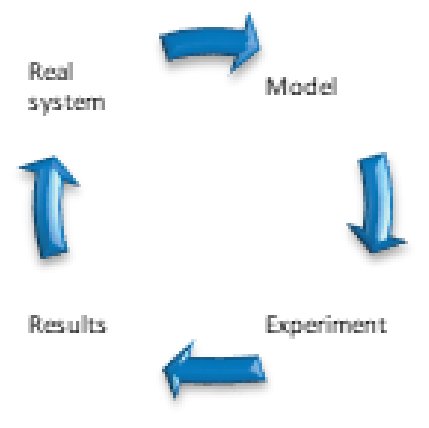

Figure 1 - Research methodology in modelling process.

Simulation is often used to solve various problems in construction management, as: optimization, predicting, allocation of resources, solving transportation problems, supply chains, selection of machinery, etc.

Simulation plays an integral role in a futuristic vision of automated project planning and control of computer modelling system for construction [1]. Many works and methods applied for the development of simulation models are based on one of the first CYCLONE simulations recommended by Halpin [2].
Simulation models are models that are related to dynamic systems, i.e. systems that change over time. Typical examples of these systems are: queues, production processes, storage, transport, etc.

AbouRizk et all presented an overview of three simulation implementations: for an earthmoving contractor (namely dynamic process interaction), an aggregate producer (continuous time-dependent) and a general contractor (static simulation) [3].

The complexity and uncertain nature of construction projects require simulation for analyzing and planning these projects. On the other hand, Genetic algorithm (GA) can be used to optimize the cost and time of a project [4] [5] [6] [7].

To improve the performance of construction operations, [8] simulation has been used to predict productivity. The Agent-Based Modelling (ABM) as an effective tool for predicting the effects of congestion on labour productivity in construction projects presented in [9]. Predicting productivity of concreting process [10] and project duration [11] presented using simulation.

In paper [12] has been proposed production processes optimization and implemented in the metallurgical enterprise information system.

Building Information Modeling (BIM) is a new approach to the application of simulations in construction. It helps architects, engineers and constructors to visualize what is to be built in simulated environment and to identify potential design, construction or operational issues [13] [14] [15].

Modern modelling is inconceivable without the use of computers that, along with various methods and software tools, provide a good space for creating complex models and working efficiently with them. Computer simulation is the performance of experiments on a model of a real system, over a period of time, which is performed on a computer (Figure 2).

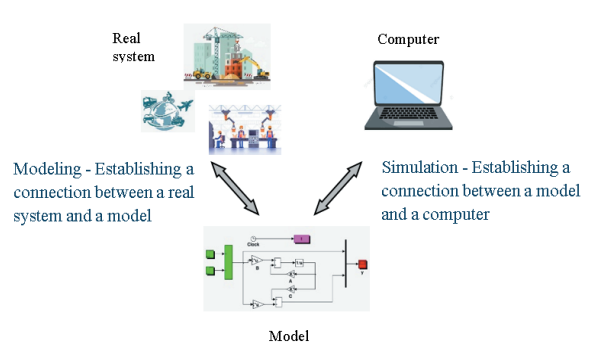

Figure 2 - Modelling and computer simulation. 
The speed of modern computers and the development of many programming languages and methods enable greater and easier application of simulation. Graphical representation of the system being modelled (e.g. presentation of the production process) and animation of the system through $2 \mathrm{D}$ and $3 \mathrm{D}$ views during simulation experiments allows easier evaluation of the logic and dynamics of simulation models and easier monitoring of model development over time.

There is a large number of ready-made software that is very widely used in the creation of simulations in construction management. Some of the software is:

- MATLAB \& Simulink - a programming environment for algorithm development, data analysis, visualization, and numerical computation. That is a programming platform designed specifically for engineers and scientists to analyze and design systems and products that transform our world;

- AnyLogic - is the only simulation tool that supports Discrete Event, Agent Based, and System Dynamics Simulation;

- FlexSim - is a powerful tool for modelling, analyzing, visualizing, and optimizing any process from manufacturing to supply chains;

- Arena - Simulation solution that assists businesses with 3D modelling, design analysis, dynamic modelling, and more;

- SimcadPro - Simulation software with interactive 2D/3D modelling. Support for Discrete Event, Continuous Flow, and Smart Agents;

- VenSim - Leading System Dynamics \& simulation solution for building high quality models of complex systems;

- Enterprise Dynamic - is a simulation software platform to design and implement simulation solutions in Industry, Logistics \& Transport, etc.

Many have ready-made libraries specializing in displaying individual processes. They enable visualization and animation through $2 \mathrm{D}$ and $3 \mathrm{D}$ views. They use different programming languages as: Matlab, $\mathrm{C}++$, Fortran, Python, JAVA methods, etc.

\section{DEVELOPMENT ALGORITHM OF SIMULATION}

The life cycle of the simulation is a series of steps that describe the individual phases of problem solving. The number of phases and the order of their execution depend on the specific situation. The basic phases of the simulation process are shown in Figure 3.

Defining the aim of the research describes problem to be solved. System identification describes system components, interaction of components, mode of operation, connections with the environment, formal presentation of the system. Collection and measurement of relevant system data, analysis of these data (selection of distributions of independent random variables, evaluation of the values of distribution parameters). Creating a conceptual model that adequately describes the system and allows solving a given problem. Making simulation software by choosing a programming language or package and creating a simulation program by writing a program or automatically generating a program based on a conceptual model. Simulation program verification is testing the simulation program according to the simulation model settings. If the verification of the program did not give satisfactory results, a return to step 5 is required. Evaluation of the simulation model implies examination of whether the simulation model adequately represents the actual system by analyzing the results. If the evaluation of the model is not successful, it is necessary to return to point 4 and make changes to the model. Planning of simulation experiments and their execution means planning and execution according to the adopted plan in order to enable fulfillment of the study goal. Analysis of the results of the experiments - during the analysis of the results, it may be necessary to supplement phase 8 , i.e. to perform additional experiments. Conclusions and recommendations are at the end of simulation. 


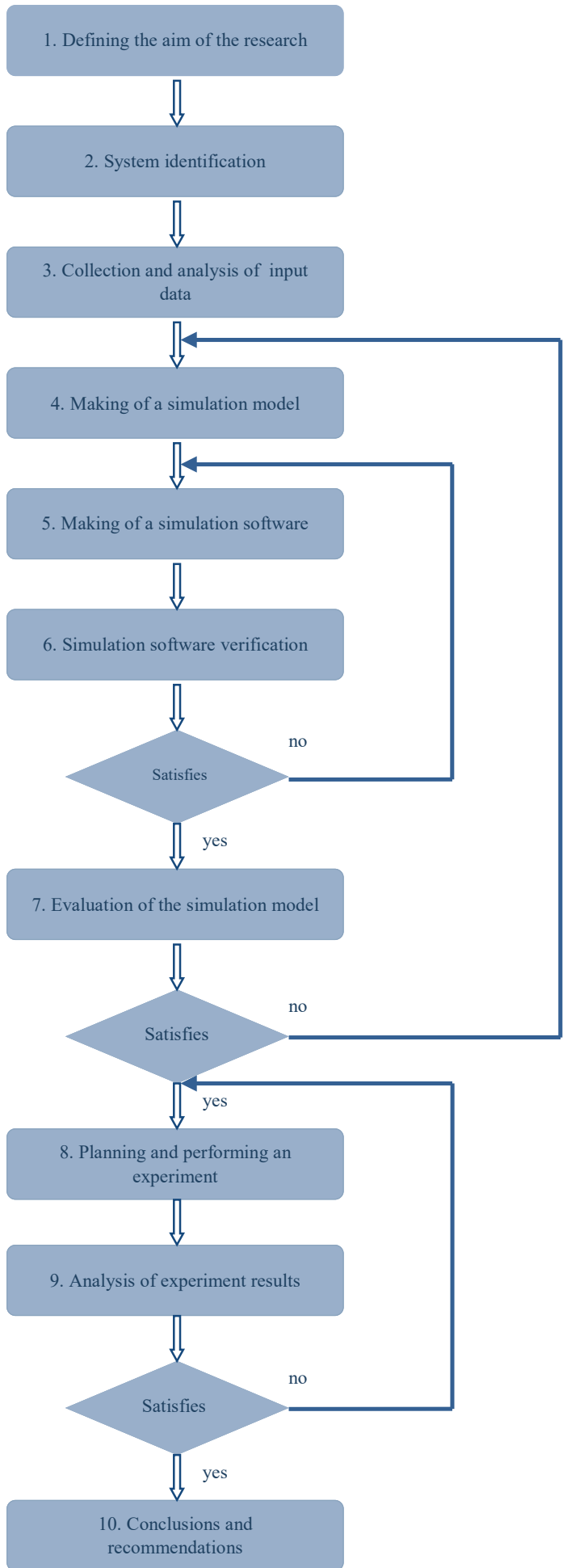

\subsection{MONTE CARLO SIMULATION}

The Monte Carlo simulation depicts stochastic processes, in which time does not play a role. It is also referred to as the method of repeated attempts and is a static type of simulation in which the creation of samples from the distribution of random variables is used in problem solving.

In construction management, Monte Carlo simulation applied to predict potential delays prior to the start of the construction project [16]. A Fuzzy Monte Carlo Simulation (FMCS) framework for risk analysis of construction projects [17] has been used successfully.

\subsection{DISCRETE EVENT SIMULATION}

Discrete Event Simulation (DES) is a method of simulation modelling of systems in which state changes occur discontinuously in time, i.e. only at certain times in time. Systems modelled in this way are dynamic and almost regularly stochastic.

The model is executed in steps, where the next state of the system depends on the current state and the current influence of the environment. The simulation describes each discrete event, moving from one event to another, resulting in a shift (increment) of the simulation time. One of the key elements in the development of discrete event simulation is the time shift mechanism. Two basic mechanisms are used: time shift for constant increment and time shift to the next event as shown in Figure 4.

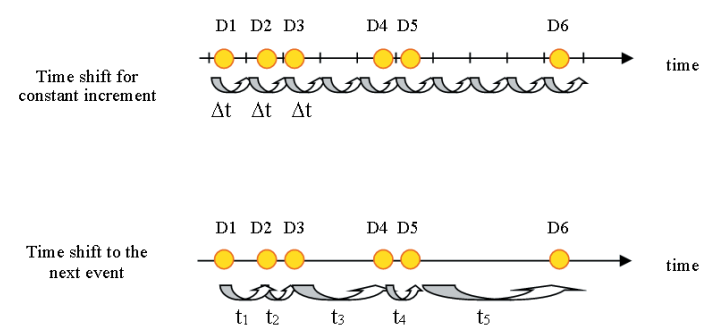

Figure 3 - Development process of simulation.

\section{TYPES AND METHODS OF SIMULATION}

Depending on how to solve the problem and consider the environment, there are 4 basic types of simulation: Monte Carlo, Discrete Event, Continuous and Mixed Simulation. 
in the previous time interval. If so, then these events are planned for the end of the interval. This time shift has a disadvantage because moving the event to the end of the time interval introduces an error into the simulation. Events that are not simultaneous in this approach are displayed as simultaneous, and then the order of their execution is determined (which may differ from the actual order). By decreasing the time increment, these errors are reduced, but the time spent on performing the simulation is increased, as well as the number of time intervals in which there are no events.

Shifting the time to the next event means moving the simulation clock to the time in which the first or more subsequent event will occur. If events are set to run at the same time, they will be executed in series as shown in Figure 5.

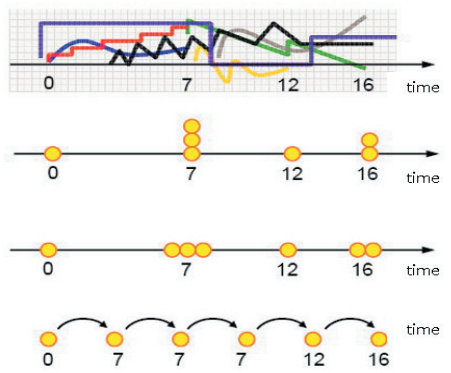

Figure 5 - Execution of simultaneous events.

The simulation ends when there are no more events or when some predefined condition for the end of the simulation is met. In this way, an error in the execution time of the event is avoided and at the same time intervals in which there are no events are skipped. This principle is more complex but also more efficient, so all key simulation languages use this mechanism. Figure 6 is shown order of execution of events.

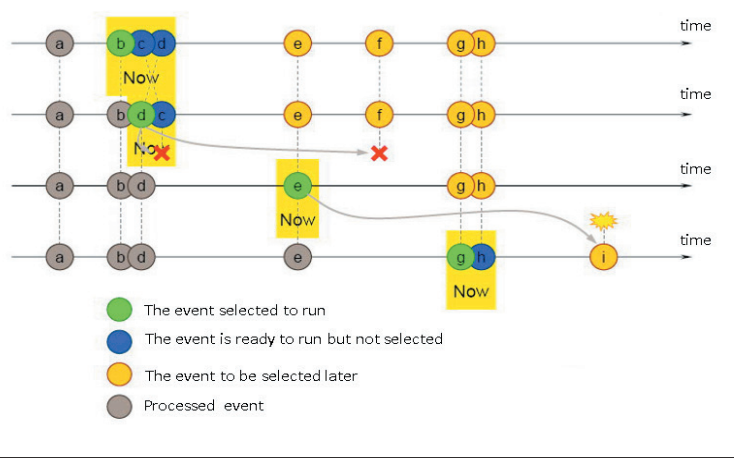

Figure 6 - Order of events execution.
An optimization methodology that integrates discrete-event simulation (DES) with a heuristic algorithm is developed to optimize dynamic resource allocation for construction scheduling [18]. A new simplified discrete-event simulation approach (SDESA) is presented through extracting the constructive features from the existing event/activity-based simulation methods [19]. Supply chain operations by looking at the logistics function of construction material suppliers a discrete event simulation approach to assess the impact of demand fluctuations on two crucial logistics performance measures; lead time and cost efficiency are presented in [20].

\subsection{CONTINUOUS SIMULATION}

Continuous simulation is used for dynamic problems in which state variables change continuously over time. Continuous simulation uses equations that describe the system in the form of change intensity. System dynamics is a methodology of research, modelling and simulation of complex dynamical systems. Feedback systems are a basic type of system that is modelled by system dynamics. Feedback models are most commonly used to model engineering, biological, social, and economic systems.

A dynamic simulation model is developed using system dynamics for supplying ready mixed concrete (RMC) [21]. Paper [22] presents a system dynamics computer model to evaluate alternative type of recycling centre under different policy and economy environments.

\subsection{MIXED SIMULATION}

Combined simulation, applies the simulation of discrete events to a single continuous model. In some types of systems, continuous simulation, as well as simulation of discrete events, cannot fully describe the mode of operation of the system. These are those systems that contain processes that run continuously and events that lead to discontinuities in the behaviour of the system. In order to model and simulate such systems, a mixed simulation has been developed that allows the integration of continuous and discrete system elements.

Discussion about the deficiencies of two traditional simulation methods - System Dynamics (SD) and discrete Event Simulation (DES) - for simulation of construction projects which can be compensated by implementing hybrid SD-DES model are presented in [23]. Research [24] argues about a hybrid SD-DES approach to model labour productivity considering the effects of 
both the context and operational level factors. The developed methodology integrates DES and SD to utilize their respective advantages in simulating construction operations [25].

\section{CONCLUSION}

The increasingly rapid progress of technology, technology and science, provides the opportunity to develop increasingly complex and comprehensive methods and techniques that are successfully applied in various fields of science. In construction management, computer simulation is widely used to solve various problems, as optimization, allocation of resources, prediction of project duration, cost, productivity, supply chain management, construction site problems, etc. Simulation has a number of advantages, such as controlled experimentation, animation, multiple uses, solving complex problems, etc. Each of the described methods is used in construction management, but most of all the method is discrete event as well as mixed simulation through the hybrid approach DES-SD. A huge amount of software for simulation have a large help to build simulation for concretely problem.

\section{REFERENCES}

[1] S. AbouRizk, "Role of simulation in construction engineering and management," Journal of construction engineering and management, vol. 136, no. 10, pp. 1140-1153, 2010.

[2] D. W. Halpin, An investigation of the Use of Simulation Networks for Modeling Construction Operations. Doctoral dissertation, University of Ilinois: Department of Civil Engineering, 1973.

[3] S. M. AbouRizk and D. Hajjar, "A framework for applying simulation in construction," Canadian journal of civil engineering, vol. 25, no. 3, pp. 604-617, 1998.

[4] S. Salimi, M. Mawlana and A. Hammad, "Performance analysis of simulation-based optimization of construction projects using high performance computing," Automation in Construction, vol. 87, pp. 158-172, 2018.

[5] H. Lu, H. Wang, Y. Xie and X. Wang, "Study on construction material allocation policies: A simulation optimization method," Automation in construction, vol. 90, pp. 201-212, 2018.

[6] S. RazaviAlavi and S. AbouRizk, "Site layout and construction plan optimization using an integrated genetic algorithm simulation framework," Journal of computing in civil engineering, vol. 31, no. 4, pp. 1-10, 2017.
[7] T. Hegazy and M. Kassab, "Resource optimization using combined simulation and genetic algorithms," Journal of construction engineering and management, vol. 129, no. 6, pp. 698-705, 2003.

[8] E. Choy and J. Y. Ruwanpura, "Predicting construction productivity using situation-based simulation models," Canadian Journal of Civil Engineering, vol. 33, no. 12, pp. 1585-1600, 2006.

[9] S. Dabirian, M. Moussazadeh, M. Khanzadi and S. Abbaspour, "Predicting the effects of congestion on labour productivity in construction projects using agent-based modelling," International Journal of Construction Management, pp. 1-24, 2021.

[10] B. Matejević, M. Zlatanović and D. Cvetković, "The simulation model for predicting the productivity of the reinforced concrete slabs concreting process," Technical Gazette, vol. 25, no. 6, pp. 1672-1679, 2018.

[11] L. D. Nguyen, D. H. Phan and L. C. Tang, "Predicting construction duration with typical construction sequences for high-rise buildings," Building Solutions for Architectural Engineering, pp. 387-396, 2013.

[12] K. Aksyonov, A. Antonova, W. Kai and O. Aksyonova, "Rules for construction of simulation models for production processes optimization," in $3 r d$ International Workshop on Radio Electronics and Information Technologies, 2018.

[13] S. Azhar, A. Nadeem, J. Y. Mok and B. H. Leung, "Building Information Modeling (BIM): A new paradigm for visual interactive modeling and simulation for construction projects," in First International Conference on Construction in Developing Countries, 2008.

[14] M. Wetter and J. Wright, "A comparison of deterministic and probabilistic optimization algorithms for nonsmooth simulation-based optimization," Building and Environment, vol. 39, no. 8, pp. 989999, 2004.

[15] R. Brown, B. Barkokebas, C. Ritter and M. Al-Hussein, "Predicting performance indicators using BIM and simulation for a wall assembly line," in 27th Annual Conference of the International Group for Lean Construction, Dublin, 2019.

[16] C. Weishaar, Predicting the impact of resource delays on a construction project's critical path using Monte Carlo simulation. Master thesis, University of Arkansas, 2018.

[17] N. Sadeghi, A. R. Fayek and R. Pedrycz, "Fuzzy Monte Carlo simulation and risk assessment in construction," Computer-Aided Civil and Infrastructure Engineering, vol. 25, no. 4, pp. 238-252, 2010.

[18] H. Zhang and H. Li, "Simulation-based optimization for dynamic resource allocation," Automation in Construction, vol. 13, no. 3, pp. 409-420, 2004. 
[19] M. Lu, "Simplified discrete-event simulation approach for construction simulation," Journal of Construction Engineering and Management, vol. 129, no. 5, pp. 537-546, 2003.

[20] C. Vidalakis, J. E. Tookey and J. Sommerville, "Demand uncertainty in construction supply chains: a discrete event simulation study," Journal of the Operational Research Society, vol. 64, no. 8, pp. 11941204, 2013.

[21] M. Park, W. Y. Kim, H. S. Lee and S. Han, "Supply chain management model for ready mixed concrete," Automation in Construction, vol. 20, no. 1, pp. 44-55, 2011.

[22] W. Zhao, H. Ren and V. S. Rotter, "A system dynamics model for evaluating the alternative of type in construction and demolition waste recycling center-The case of Chongqing, China," Resources, Conservation and Recycling, vol. 55, no. 11, pp. 933944, 2011.

[23] S. Moradi, F. Nasirzadeh and F. Golkhoo, "A hybrid SD-DES simulation approach to model construction projects," Construction innovation, vol. 15, no. 1, pp. 66-83, 2015.

[24] S. Moradi, F. Nasirzadeh and F. Golkhoo, "Modeling labor productivity in construction projects using hybrid SD-DES approach," Scientia Iranica, vol. 24, no. 6, pp. 2752-2761, 2017.

[25] H. Alzraiee, O. Moselhi and T. Zayed, "A hybrid framework for modeling construction operations using discrete event simulation and system dynamics," in Construction Research Congress 2012: Construction Challenges in a Flat World, 2012. 